Review www.pjkd.com.pk

\title{
Covid-19 and Acute Kidney Injury: Recent Updates
}

\section{Salman Tahir Shafi}

Department of Nephrology

Sharif Medical and Dental College

Lahore, Pakistan

\begin{abstract}
:
In January 2020, the pathogen was identified and named by the World Health Organization as Severe Acute Respiratory Syndrome Coronavirus 2 (SARS-COV-2). The consequent SARS-CoV-2-related disease was defined as coronavirus disease 2019 (COVID-19). As data emerged about characteristics of the disease, it was found to be associated with increased risk of acute kidney injury (AKI). We explore the recent literature and reports emerging from the epicenters of the pandemic to help our viewers understand the nature of AKI among these patients.
\end{abstract}

Key words: SARS virus, COVID-19, Pandemic, AKI, acute kidney injury, pneumonia, acute tubular injury, ARDS.

\section{Corresponding Author}

Professor Dr. Salman Tahir Shafi

Department of Nephrology

Sharif Medical \& Dental College

Lahore, Pakistan

Email: salmanshafi@email.com

Received: April 6,2020. Accepted April 19,2020.

PJKD 2020(4);2:225-227

\section{Introduction}

A series of unexplained pneumonia cases were reported in the city of Wuhan, the capital of Hubei province in central China in December 2019. In January 2020, the pathogen was identified and named by the World Health Organization (WHO) as Severe Acute Respiratory Syndrome Coronavirus 2 (SARS-COV-2). The consequent SARS-CoV-2-related disease was defined as coronavirus disease 2019 (COVID-19) ${ }^{1}$. On March 11, 2020 it was declared as pandemic by WHO and so far has affected over 1 million people across the globe ${ }^{2}$. As data emerged about characteristics of the disease, it was found to be associated with increased risk of acute kidney injury (AKI) ${ }^{3,4}$ The purpose of this review is to explore recent literature on epidemiology, pathogenesis and outcomes of patients with COVID-19 and AKI. Of note, the information is preliminary and rapidly evolving with emerging publications.

\section{Epidemiology}

Several studies with the exception of few have reported increased incidence of AKI in patients with COVID-19 infection. Reported incidence of AKI in various studies including unpublished literature is listed in Table 1. Of note, there is wide variation in reported incidence of AKI ranging from 0-29\%. This is partly explained by mostly single center studies from China with limited sample size with the exceptions of studies from Guan and Cheng et al. In addition, difference in severity of illness at different centers may be a plausible explanation for difference in incidence of AKI among different reports.

The study by Cheng et al. was specifically focused on incidence of AKI and its impact on outcomes of Covid-19 patients. There were two additional important observations in this study. First, among patients with elevated baseline creatinine, AKI was more common (9.1 vs. 2.0\%), more severe (Stage III AKI - 3.6\% vs. 0.7\%) and happened sooner (2 vs. 6 days) compared to those with normal baseline creatinine. Second, abnormal renal parameters were noticed even on admission with proteinuria, hematuria, elevated blood urea nitrogen (BUN) and creatinine were present in $44 \%, 26.9 \%, 15.5 \%$ and $14.1 \%$ respectively ${ }^{10}$.

In another data by Zhen Li et al (unpublished), a similar remarkable proportion of patients exhibited abnormalities of renal parameters at admission to the hospital, including 59\% with proteinuria, 44\% with hematuria, $14 \%$ with elevated BUN and $10 \%$ with elevated serum creatinine. Most of these abnormalities were mild. However, overall elevation of BUN and creatinine was found in $31 \%$ and $22 \%$ of all patients during hospital stay ${ }^{17}$.

\section{Pathogenesis of AKI}

Pathogenesis of AKI in patients with COVID-19 is likely multifactorial ${ }^{10,18}$. The plausible mechanisms and supporting evidence or rationale is listed in table 2. Of note, presence of viral RNA in urine has not been linked to AKI and is only sporadically demonstrated. Wang L et al found viral RNA in urine in $7.5 \%$ of 53 tested patients of whom none developed $\mathrm{AKI}^{5}$. In another study, none of the 72 tested patients had viral RNA in urine ${ }^{8}$, while Guan et al found viral RNA in one urine specimen but it is not clear how many patients were tested ${ }^{6}$ 


\section{COVID-19 and AKI}

Table 1: Incidence of acute kidney injury in COVID-19 patients as presented in the recent literature.

\begin{tabular}{|c|c|c|c|}
\hline Author & Location \& Number of Patients & Incidence of AKI & CRRT* \\
\hline $\begin{array}{l}\text { Wang L } \\
\text { Am J Nephrol } \\
\text { March 2020 }\end{array}$ & $\begin{array}{l}\text { Wuhan } \\
\mathrm{N}=116\end{array}$ & $0 \%$ & \\
\hline $\begin{array}{l}\text { Guan NEJM } \\
\text { Jan } 2020^{6}\end{array}$ & $\begin{array}{l}30 \text { Regions in China } \\
\mathrm{N}=1099\end{array}$ & $0.5 \%$ & $0.8 \% * *$ \\
\hline Chen et al Lancet Jan $2020^{\prime}$ & $\begin{array}{l}\text { Wuhan } \\
\mathrm{N}=99\end{array}$ & $3 \%$ & $9 \% * *$ \\
\hline Wang et al JAMA Feb $2020^{8}$ & $\begin{array}{l}\text { Wuhan } \\
\mathrm{N}=138\end{array}$ & $3.6 \%$ & $1.45 \%$ \\
\hline Zhang et al Med Rxiv Feb $2020^{9}$ & $\begin{array}{l}\text { Wuhan } \\
\mathrm{N}=221\end{array}$ & $4.5 \%$ & $2.3 \%$ \\
\hline $\begin{array}{l}\text { Cheng et al Kidney Int. March } \\
2020^{10}\end{array}$ & $\begin{array}{l}\text { Shanghai } \\
N=701\end{array}$ & $5.1 \%$ & \\
\hline Huang et al Lancet Jan $2020^{11}$ & $\begin{array}{l}\text { Wuhan } \\
\mathrm{N}=41\end{array}$ & $7 \%$ & \\
\hline Chen et al BMJ March 2020 & $\begin{array}{l}\text { Wuhan } \\
\mathrm{N}=274,113 \text { (Deceased) }\end{array}$ & $11 \%, 25 \%$ in deceased & $1 \%$ \\
\hline Zhou et al Lancet March $2020^{15}$ & $\begin{array}{l}\text { Wuhan } \\
\mathrm{N}=191\end{array}$ & $15 \%, 50 \%$ in deceased & $5 \%$ \\
\hline Arentz et al JAMA March $2020^{14}$ & $\begin{array}{l}\text { Seattle USA } \\
\mathrm{N}=21\end{array}$ & $19 \%$ & \\
\hline $\begin{array}{l}\text { Diao et al MedRxiv } \\
\text { March } 2020^{15}\end{array}$ & $\begin{array}{l}\text { Wuhan } \\
\mathrm{N}=85\end{array}$ & $23 \%$ & \\
\hline $\begin{array}{l}\text { Yang et al Lancet Resp Med Feb } \\
2020^{16}\end{array}$ & $\begin{array}{l}\text { Wuhan } \\
\text { N=52 (ICU) }\end{array}$ & $29 \%$ (ICU) & $17 \%$ \\
\hline
\end{tabular}

*CRRT - Continuous Renal replacement therapy

**Higher utilization of CRRT compared to incidence of AKI may reflect an attempt to achieve negative fluid balance in patients with Adult respiratory distress syndrome (ARDS) or remove inflammatory mediators in septic patients, though it was not clearly documented in respective papers. Possibility of typographic error cannot be excluded either.

Table 2: Possible mechanisms of acute kidney injury in patients with COVID-19 infection.

\begin{tabular}{|l|l|}
\hline Mechanisms & Rationale/Evidence \\
\hline $\begin{array}{l}\text { Direct viral cytopathic } \\
\text { effect }\end{array}$ & $\begin{array}{l}\text { Abundant expression of angiotensin converting enzyme II (ACE II) receptor in kidneys } \\
\text { which is used by Novel corona virus for cell entry,1,9} \\
\text { Demonstration of SARS-CoV-2 nucleocapsid (NP) protein on immunohistochemistry in } \\
\text { renal tubules in an autopsy study }\end{array}$ \\
\hline Acute tubular necrosis & $\begin{array}{l}\text { Contributing factors may include volume depletion, cytokine storm, hypoxia, shock or } \\
\text { rhabdomyolysis } \\
\text { Demonsto, } \\
\text { tubulointerstitium and C5b-9 deposition on tubules in an autopsy study }\end{array}$ \\
\hline $\begin{array}{l}\text { Immune complex } \\
\text { mediated mechanism } \\
\text { due to deposition of } \\
\text { viral antigens (less } \\
\text { likely) }\end{array}$ & $\begin{array}{l}\text { Findings of proteinuria and hematuria in two studies } \\
\text { specific. }\end{array}$ \\
\hline
\end{tabular}

\section{Management of AKI}

There is not much details in published literature regarding strategies for management of AKI. It is likely that these patients were managed in standard way like any other critically ill patient in ICU. Fluid conservative strategy (or negative fluid balance strategy) was likely employed especially in patients with ARDS ${ }^{22}$. This is supported by data from Guan et al and Chen et al, in which 9 patients had CRRT despite only 6 and 3 patients developing AKI respectively (likely to achieve negative fluid balance) ${ }^{6,7}$. Choice of renal replacement therapy appears to be CRRT in various studies.

Guidelines mainly based on opinion and existing evidence for other critically ill patients have emerged for patients with COVID-19 in intensive care unit (ICU) ${ }^{23}$ who are more likely to develop AKI. Key features of these guidelines which may be relevant to the practice of nephrologists are listed as follows:-

1) Strict infection control practices

2) Conservative fluid strategy

3) Use of crystalloids rather than colloids and avoidance of hydroxyethyl starch

4) Use of nor-epinephrine for shock followed by vasopressin or epinephrine and avoidance of dopamine

5) Use of steroids for refractory septic shock.

Indications of hemodialysis are likely be standard with utilization of CRRT wherever available. Others can use prolonged intermittent renal replacement therapy. In patients with ARDS and AKI, RRT may be required sooner if unable to achieve conservative fluid balance. Strict adherence to recommended infection control practices should be observed during dialysis treatment. 


\section{COVID-19 and AKI}

\section{Prognosis}

There is very limited information on impact on AKI on patient outcomes in published literature. In a study by Cheng et al, AKI was independently associated with increased mortality (Hazard ratio 2.2, 95\% CI 1.1-4.4). Of significance, among those with elevated baseline creatinine, development of AKI resulted in increased incidence of death (30.9\% vs. $9.2 \%)$ compared to those with normal baseline serum creatinine. In addition, elevated BUN, creatinine, proteinuria and hematuria at admission were also found to be independent predictors of mortality. ${ }^{10,24}$ Zhen Li et al (un-published) also found that AKI was associated with $~ 5.3$ times increased risk of mortality in an unadjusted analysis ${ }^{17}$. Similarly, Zhou et al found association of serum creatinine $>133 \mu \mathrm{mol} / \mathrm{L}$ with increased mortality in an unadjusted analysis but not in a multivariate model ${ }^{13}$.

\section{Conclusion}

The research on COVID-19 and especially on its renal implications is still evolving. Based on limited literature, it appears that patients with COVID-19 and especially those needing intensive care are susceptible to renal injury due to either or combination of direct viral cytopathic effect or inflammatory response and its consequences. Management strategies will include monitoring of renal function, optimization of hemodynamic parameters, tailoring fluid balance strategies based on respiratory status, avoidance of nephrotoxic medications and initiation of renal replacement therapy for standard indications.

\section{Conflict of Interest: None declared}

\section{References}

1. Zhou P, Yang X Lou, Wang XG, et al. A pneumonia outbreak associated with a new coronavirus of probable bat origin. Nature. 2020;579(7798):270-273. doi:10.1038/s41586-020-2012-7

2. WHO Director-General' s opening remarks at the media briefing on COVID-19 - 11 March 2020. https://www.who.int/dg/speeches/detail/who-director-general-s-opening-remarks-at-the-media-briefing-on-covid-19---11-march-2020. Accessed April 5, 2020.

3. Perico L, Benigni A, Remuzzi G. Should COVID-19 Concern Nephrologists? Why and to What Extent? The Emerging Impasse of Angiotensin Blockade. Nephron. March 2020:1-9. doi:10.1159/000507305

4. Zhang F, Liang Y. The potential risk of kidney vulnerable to novel coronavirus 2019 infection. Am J Physiol Renal Physiol. March 2020. doi:10.1152/ajprenal.00085.2020

5. Wang L, Li X, Chen H, et al. Coronavirus Disease 19 Infection Does Not Result in Acute Kidney Injury: An Analysis of 116 Hospitalized Patients from Wuhan, China. Am J Nephrol. March 2020:1-6. doi:10.1159/000507471

6. Guan W, Ni Z, Hu Y, et al. Clinical Characteristics of Coronavirus Disease 2019 in China. N Engl J Med. February 2020:NEJMoa2002032. doi:10.1056/NEJMoa2002032

7. Chen N, Zhou M, Dong X, et al. Epidemiological and clinical characteristics of 99 cases of 2019 novel coronavirus pneumonia in Wuhan, China: a descriptive study. Lancet. 2020;395(10223):507-513. doi:10.1016/S0140-6736(20)30211-7

8. Wang D, Hu B, Hu C, et al. Clinical Characteristics of 138 Hospitalized Patients with 2019 Novel Coronavirus-Infected Pneumonia in Wuhan, China. JAMA - J Am Med Assoc. 2020;323(11):1061-1069. doi:10.1001/jama.2020.1585

9. Zhang G, Hu C, Luo L, et al. Clinical features and outcomes of 221 patients with COVID-19 in Wuhan, China. medRxiv. March 2020:2020.03.02.20030452. doi:10.1101/2020.03.02.20030452

10. Cheng Y, Luo R, Wang K, et al. Kidney disease is associated with in-hospital death of patients with COVID-19. Kidney Int. 2020;0(0). doi:10.1016/j.kint.2020.03.005

11. Huang C, Wang Y, Li X, et al. Clinical features of patients infected with 2019 novel coronavirus in Wuhan, China. Lancet. 2020;395(10223):497-506. doi:10.1016/S0140-6736(20)30183-5

12. Chen T, Wu D, Chen H, et al. Clinical characteristics of 113 deceased patients with coronavirus disease 2019: retrospective study. BMJ. 2020;1091(March):m1091. doi:10.1136/bmj.m1091

13. Zhou F, Yu T, Du R, et al. Clinical course and risk factors for mortality of adult inpatients with COVID-19 in Wuhan, China: a retrospective cohort study. Lancet. 2020;395(10229):1054-1062. doi:10.1016/S0140-6736(20)30566-3

14. Arentz M, Yim E, Klaff L, et al. Characteristics and Outcomes of 21 Critically Ill Patients With COVID-19 in Washington State. Jama. 2020;4720:2019-2021. doi:10.1001/jama.2020.4326

15. Diao B, Feng Z, Wang C, et al. Human Kidney is a Target for Novel Severe Acute Respiratory Syndrome Coronavirus 2 (SARS-CoV-2) Infection. medRxiv. March 2020:2020.03.04.20031120. doi:10.1101/2020.03.04.20031120

16. Yang X, Yu Y, Xu J, et al. Clinical course and outcomes of critically ill patients with SARS-CoV-2 pneumonia in Wuhan, China: a singlecentered, retrospective, observational study. Lancet Respir Med. 2020. doi:10.1016/S2213-2600(20)30079-5

17. Volunteers A-2019-nCoV, Li Z, Wu M, et al. Caution on Kidney Dysfunctions of 2019-nCoV Patients. medRxiv. March 2020:2020.02.08.20021212. doi:10.1101/2020.02.08.20021212

18. Rismanbaf A, Zarei S. Liver and Kidney Injuries in COVID-19 and Their Effects on Drug Therapy; a Letter to Editor. Arch Acad Emerg Med. 2020;8(1):e17. http://www.ncbi.nlm.nih.gov/pubmed/32185369. Accessed April 4, 2020.

19. Pan X, Xu D, Zhang H, Zhou W, Wang L, Cui X. Identification of a potential mechanism of acute kidney injury during the COVID-19 outbreak: a study based on single-cell transcriptome analysis. Intensive Care Med. March 2020:1-3. doi:10.1007/s00134-020-06026-1

20. Valizadeh R, Baradaran A, Mirzazadeh A, VKS Bhaskar L. Coronavirus-nephropathy; renal involvement in COVID-19. J Ren Inj Prev J Ren Inj Prev. 2020;9(2):18. doi:10.34172/jrip.2020.18

21. Cheng Y, Luo R, Wang K, et al. Kidney impairment is associated with in-hospital death of COVID-19 patients. medRxiv. February 2020:2020.02.18.20023242. doi:10.1101/2020.02.18.20023242

22. Matthay MA, Aldrich JM, Gotts JE. Treatment for severe acute respiratory distress syndrome from COVID-19. Lancet Respir Med. 2020;0(0). doi:10.1016/S2213-2600(20)30127-2

23. Alhazzani W, Møller MH, Arabi YM, et al. Surviving Sepsis Campaign: guidelines on the management of critically ill adults with Coronavirus Disease 2019 (COVID-19). Intensive Care Med. March 2020:1-41. doi:10.1007/s00134-020-06022-5

24. Mubarak M, Nasri H. COVID-19 nephropathy; an emerging condition caused by novel coronavirus infection. J Nephropath 2020;9(3):e21 